TABLE II

Deviations of the Field of the Varieties from their own Means in Different Years

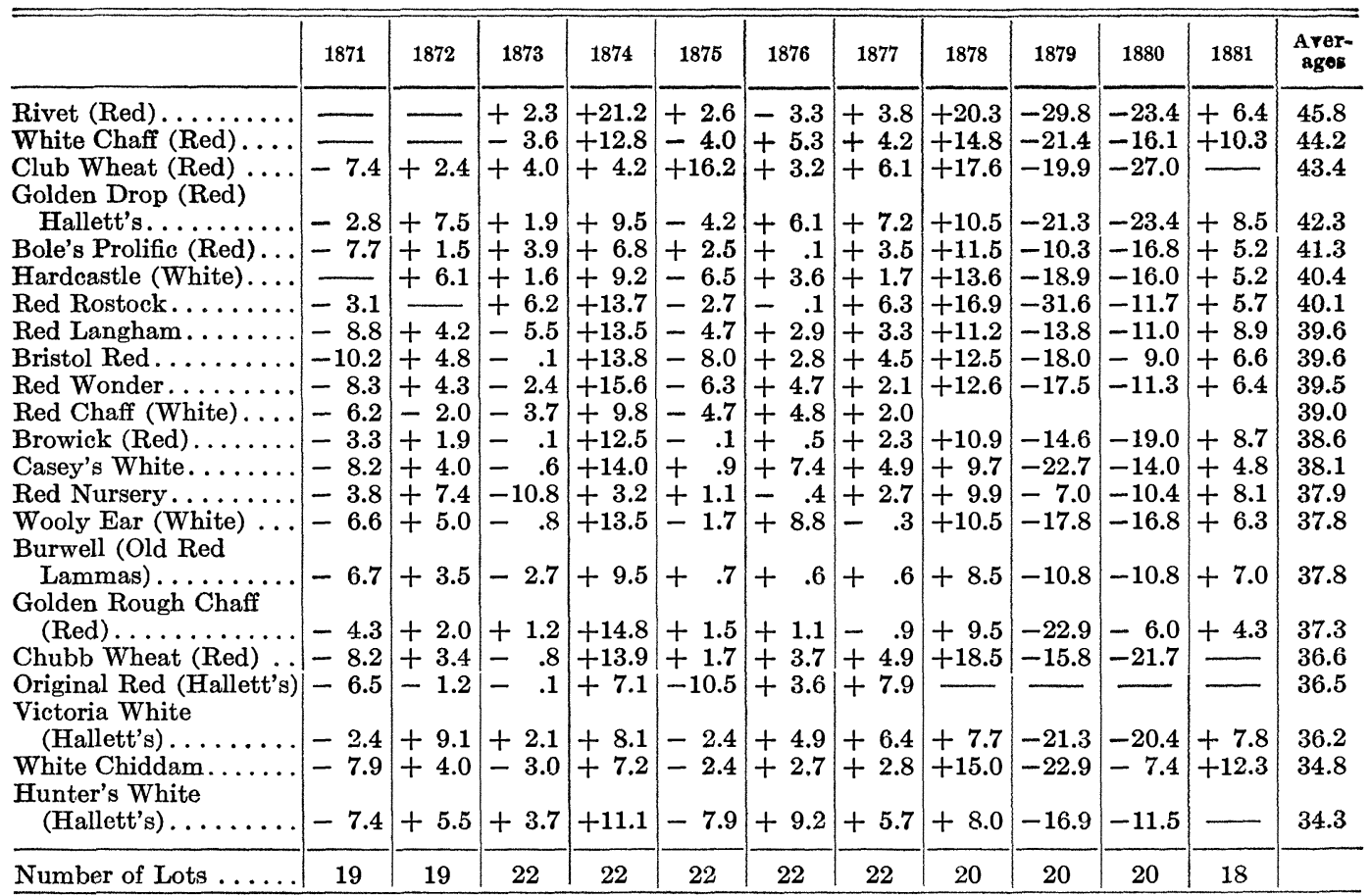

Is it not time for a concerted and systematic effort on the part of those interested in agricultural science to put this important problem on a sound basis, biologically and statistically?

PRING HARBOR, L. I., July 17, 1912

THE VISCOSITY OF GASES AND THE BUNSEN FLAME

IN the long experience with the Bunsen flame, which I had some years ago, when these flames were still the only available approach to high temperatures on a large scale, it always struck me as curious that a flame which was quite colorless when the burner was cold should turn whitish when coming from a hot burner. The effect is marked when the combustion gases issue from a long narrow slit, cut from end to end of a horizontal tube 4 inches long. When the eap is removed from the remote end of such a tube, the flame will sputter, showing large excess of air; on clos- ing the tube, it is long narrow pure blue line, burning quietly. When the tube gets hot the flame shows an internal white margin, which again vanishes when the tube is cooled, by water, for instance.

It is clear that for the hot tube there is a deficiency of air, in spite of the excessive room for ingress of air below. Since the gas supplied to the jet remains constant, the intake of air depends upon the rapidity of the escape of gases at the flame. The more rapid the escape, the greater the admixture for the same quantity of gas, and the nearer the flame approached to that of a blast lamp. Hence when the tube at the slot is heated, the escape of gas is retarded owing to the increased viscosity of air at high temperatures. Relatively little air is taken in because the escape of combustion gases is relatively small. This simple experiment, therefore, has a direct and interesting bearing on the viscosity of gases.

\section{BROWN UNIVERSITY}

\section{Barus}

